\section{Development of synovial membrane in the temporomandibular joint of the human fetus}

\author{
L.O. Carvalho de Moraes, ${ }^{1,2}$ \\ R.C. Tedesco, ${ }^{1}$ L.A. Arraéz-Aybar, ${ }^{3}$ \\ O. Klein, ${ }^{2}$ J.R. Mérida-Velasco, ${ }^{3}$ \\ L.G. Alonso' \\ 'Discipline of Descriptive and \\ Topographic Anatomy, Department of \\ Morphology and Genetics, Federal \\ University of São Paulo, Brazil \\ 2Department of Orofacial Sciences and \\ Program in Craniofacial and Mesenchymal \\ Biology, University of California, San \\ Francisco, CA, USA \\ ${ }^{3}$ Department of Anatomy and \\ Embryology, Medical School, University \\ Complutense of Madrid, Spain
}

\section{Abstract}

The development of the synovial membrane was analyzed in serial sections of 21 temporomandibular joints of human fetuses at 9 to 13 weeks of gestation. Sections of two fetuses at 12 weeks of development were used to perform immunohistochemical expression of the markers CD68 and Hsp27 on the synovial lining. Macrophage-like type A and fibroblast-like type B cells, which express CD68 and Hsp27, respectively, were observed at the twelfth week of development. Our results suggest that the development of the synovial membrane is related to the vascularization of the joint and the formation of the articular cavities.

\section{Introduction}

Compared with the synovial joints of the limbs, the temporomandibular joint (TMJ) develops relatively late. By the eighth week of development in humans (0'Rahilly's stage 23), the joint cavity of the elbows, hips, and knees are already visible, while the TMJ has only mesenchymal condensation of the mandibular condyle, articular disc, and squamous part of the temporal bone, and no evidence of its cavity. ${ }^{1-4}$

According to Mérida-Velasco et al., ${ }^{1,2}$ by approximately week nine, the condylar chondrification begins in the center of the condylar blastemal. The inferior joint cavity starts to develop at the end of the ninth week, as the density of the mesenchymal cells in the central region decreases because of their differentiation into fibroblasts, constituting the primordium of the articular disc. As the density of the ectomesenchyme decreases, small adjacent spaces between the cells coalesce, forming the inferior joint cavity between the future articular disc and the mandibular condyle. In the $10^{\text {th }}$ week, these newly differentiated fibroblasts become more compact, forming collagen fibers and the articular disc, but there is still no sign of the superior joint cavity. ${ }^{1,5-7}$ In the eleventh week, the organization of the superior joint cavity begins between the squamous part of the temporal bone and the articular disc. ${ }^{1,2}$ More detailed studies of the TMJ development, as well as of their condylar cartilage, articular disc and the matrix proteins on the fetus development were researched through immunohistochemistry and in situ hybridization. ${ }^{8,9}$

The synovial membrane is an important anatomic element of the TMJ. Morphologically, the synovial membrane consists of two layers: an inner cell layer called the intima and a support layer called the vascular subintima, which mixes with the fibrous capsule. The intima consists of cells embedded in an amorphous, fiber-free matrix with an approximate thickness of one to four cells. The subintima consists of loose connective tissue with blood vessels, spread-out fibroblasts, macrophages, mastocytes, adipose cells, and some elastic fibers that prevent membrane folding. ${ }^{10-15}$

The intima contains macrophage-like type A cells with phagocytic ability, and fibroblast-like type B cells that synthesize proteins, glycoproteins, and proteoglycans. ${ }^{12,13,16-19}$

Immunohistochemical techniques allowed to detect macrophage-like type A cells and fibroblast-like type B cells by using antimacrophage and anti-fibroblast antibodies, respectively. Grabowski et al.,${ }^{20}$ Nozawa-Inoue et al..$^{21}$ and Suzuki et al. ${ }^{22}$ successfully marked macrophage-like type A cells with the antibodies 0X6, EDI, CD68, and CD31. On the other hand, the laminin antibodies Mab67, VCAM-1, lumican, fibromodulin, UDPGD, and Hsp25 mark fibroblast-like type B cells, and have been used in studies of the synovial intima. ${ }^{23-30}$ Although a number of groups have studied about the synovial membrane of the TMJ of children, adults, and animals models, there is little in the literature regarding the development of this structure in human fetuses. ${ }^{12}$ Understanding the morphology of fetal development is important not only to better understand the embryological steps that culminate with the individual's anatomic constitution but also to elucidate the intrinsic mechanisms that may be involved in congenital anomalies and postnatal pathologies. ${ }^{31}$

This study aims to improve the anatomic and histologic knowledge of the synovial membrane by determining when the synovial
Correspondence: Luis Otavio Carvalho de Moraes, Disciplina de Anatomia Descritiva e Topográfica, Departamento de Morfologia e Genética, Escola Paulista de Medicina da Universidade Federal de São Paulo, Rua Botucatu 740 - Edifício Leitão da Cunha (térreo), Vila Clementino, 04023-900 São Paulo, SP, Brazil.

Tel. +55.11.5576-4848 extension 2210 Fax: $+55.11 .5571-7597$.

E-mail: luisotavio27@yahoo.com.br

Key words: Synovial membrane; immunohistochemistry; temporomandibular joint; fetus.

Conflict of interest: the authors declare no potential conflict of interest.

Contributions: all authors contributed equally to this work and approved the version to be published.

Acknowledgments: special thanks go to the Coordenação de Aperfeiçoamento de Pessoal de Nível Superior (CAPES) for financial support.

Received for publication: 21 September 2015. Accepted for publication: 9 November 2015.

This work is licensed under a Creative Commons Attribution NonCommercial 3.0 License (CC BYNC 3.0).

(C) Copyright L.O. Carvalho de Moraes et al., 2015 Licensee PAGEPress, Italy

European Journal of Histochemistry 2015; 59:2569 doi:10.4081/ejh.2015.2569

memL.0. Carvalho de Moraesbrane begins to form during morphogenesis and the chronological occurrence and dynamics of cell types present in the synovial membrane. It also aims to analyze the morphological differences that appear during the development of the superior and inferior articular cavities.

\section{Materials and Methods}

We studied twenty one human fetuses from the Institute of Embryology of the University Complutense of Madrid and Associação de Fundo Incentivo à Pesquisa. The specimens ranged from $40 \mathrm{~mm}$ to $100 \mathrm{~mm}$ greatest length (GL) with the following ages: three nine-week fetuses; four ten-week fetuses; five elevenweek fetuses; four twelve-week fetuses; five thirteen-week fetuses; post-conception age was determined by measuring GL and external and internal criteria. ${ }^{3,32}$ All specimens were from ectopic pregnancies or spontaneous abortions, and there were no signs of malformation. All fetuses were fixed in $10 \%$ formalin and separated into groups studied by light 
microscopy and immunohistochemistry.

All samples were decalcified in EDTA for 21 days and rinsed with tap water for $10 \mathrm{~min}$. They were then fixed in $10 \%$ formaldehyde for $24 \mathrm{~h}$. Next, they were dehydrated as follows: one 24-h immersion in 50\% ethanol; two 6-h immersions in $70 \%$ ethanol; and two 6 -h immersions in absolute ethanol. Finally, the samples were cleared by a 2 -h treatment with xylol and fixed in paraffin. Semi-serial, frontal, and sagittal $4 \mu \mathrm{m}$ cuts of the TMJ were made by the microtome Leica, model RM $2035^{\circledR}$. The sections, which included three spatial planes, were stained with hematoxylin-eosin (HE), azocarmine, and Masson's trichrome stain. 33,34

Ten samples with gestational ages of 12 weeks were selected for immunohistochemistry. The following antibodies were used: CD68 (Santa Cruz Biotechnology, Santa Cruz, CA, USA); monoclonal anti-human $\operatorname{IgG}_{1}$ produced in mouse and diluted to 1:100 and Hsp27 (Santa Cruz Biotechnology); monoclonal antihuman $\operatorname{IgG}_{1}$ produced in mouse and diluted to 1:150 using the indirect immunoenzyme method in three stages and the streptavidinbiotin-peroxidase complex. ${ }^{35}$ The antibodies CD68 and HSP27 react with the cells macrophage-like type A and fibroblast-like type $\mathrm{B}$, respectively. The positive controls for the antibodies CD68 and Hsp27 were palatine tonsil and breast adenocarcinoma, respectively. The negative controls were the same cases used as positive controls, but a buffer instead of the primary antibody was used for immunohistochemical incubation.

The study was approved by the ethics committee of the Faculty of Medicine of the University Complutense of Madrid and the Federal University of São Paulo Research Ethics Committee.

\section{Results}

\section{Week 9-10}

All specimens studied during the ninth week showed small spaces or clefts between the primordium of the articular disc and the mandibular condyle that defined the initial formation of the inferior joint cavity. Some vascular branches were located in the periphery of the articular disc primordium (Figure 1A). All specimens studied during the tenth week showed the organization of the inferior joint cavity complete although crossed by a few tracts of connective tissue. There was still no sign of the superior joint cavity (Figure 1B).

\section{Week 11}

Blood vessels in the inferior part of the
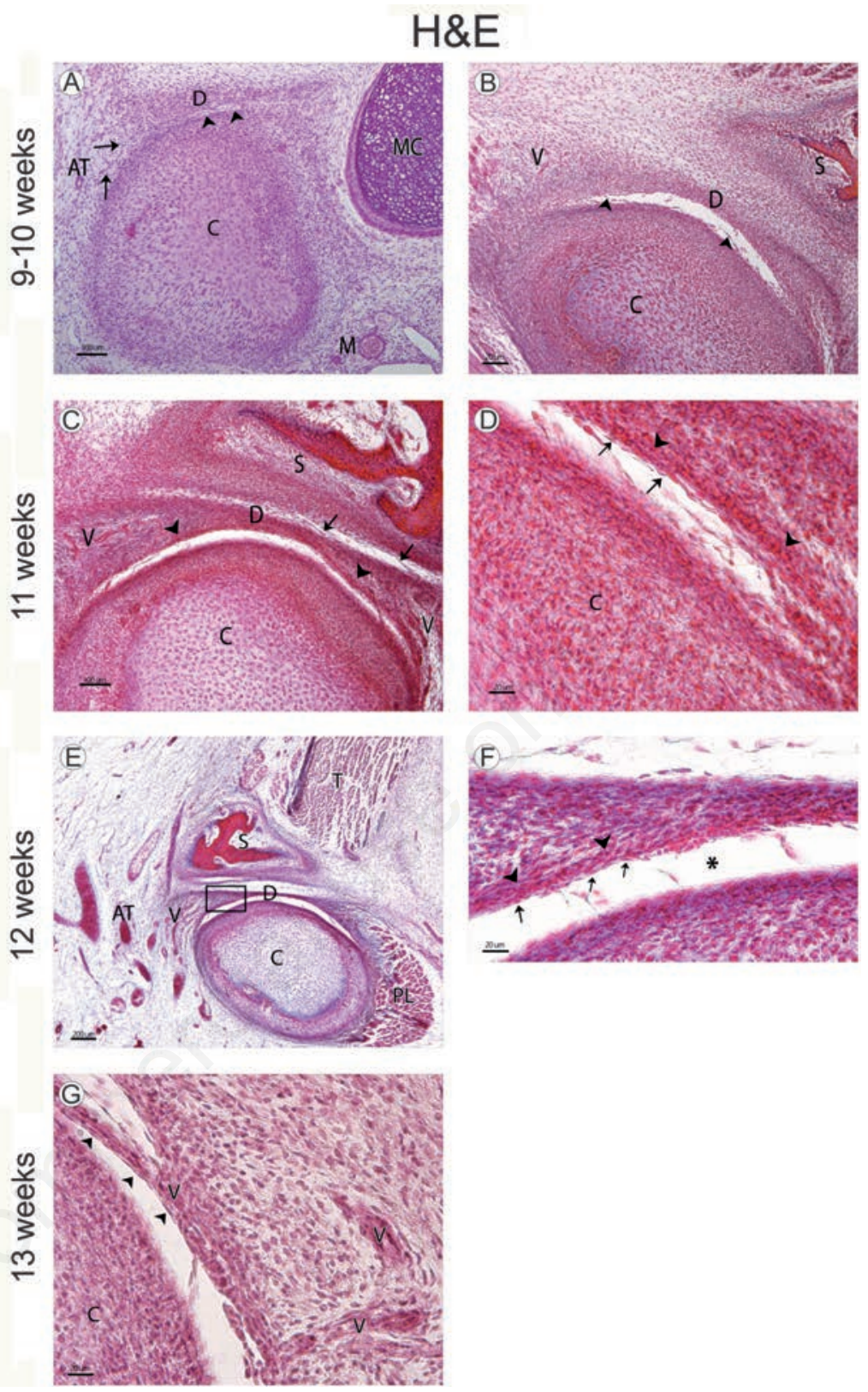

Figure 1. A) Human fetus (38 mm GL; week 9 of development); sagittal section stained with hematoxylin-eosin; the mandibular condyle (C) begins its chondrification; small spaces (arrowheads) show initial inferior joint cavity formation; D, articular disc; C, mandibular condyle; M, maxillary artery; AT, superficial temporal artery; MC, Meckel's cartilage; arrows, vessel. B) Human fetus (48 mm GL; week 10 of development); frontal section stained with hematoxylin-eosin; the inferior joint cavity continues its organization between the articular disc (D) and the mandibular condyle (C); arrowheads, tracts of connective tissue; $\mathrm{S}$, squamous part of the temporal bone; V, vessel. C) Human fetus (65 mm GL; week 11 of development); frontal section stained with hematoxylin-eosin; the organization of the superior joint cavity began between the squamous part of the temporal bone (S) and the articular disc (D); arrowheads, vessels in the inferior partof the primordium of the articular disc; $\mathrm{C}$, mandibular condyle; $\mathrm{V}$, vessels; arrows, tracts of connective tissue. D) Human fetus (65 mm GL; week 11 of development); magnification of panel A; fusiform-like cells (arrows) separate the vessels (arrowheads) of the articular disc from the inferior articular cavity; $C$, mandibular condyle. E) Human fetus $(80 \mathrm{~mm}$ GL; week 12 of development); frontal section stained with hematoxylin-eosin; $D$, articular disc; C, mandibular condyle; PL; lateral pterygoid muscle; T, temporalis muscle; $S$, squamous part of the temporal bone; V, vessels; AT, superficial temporal artery. F) Human fetus ( $80 \mathrm{~mm}$ GL; week 12 of development); magnification of the squared area in panel A. Vessels (arrowheads), fusiform-like cells (arrows); inferior articular cavity (asterisk). G) Human fetus (97 mm GL; week 13 of development) vessels surrounded by fusiform cells (arrowheads) form the primordium of the synovial villi; V, vessels; $C$, mandibular condyle. 
articular disc primordium were seen during the eleventh week. Fusiform-like cells separate the vessels of the inferior articular cavity (Figure $1 \mathrm{C}, \mathrm{D}$ ).

The organization of the superior joint cavity began between the squamous part of the temporal bone and the primordium of the articular disc. The superior joint cavity was crossed by few tracts of the connective tissue (Figure 1C). Numerous vessels were seen in the lateral and medial parts of the TMJ (Figure 1D).

\section{Week 12}

All specimens studied this week showed the joint cavities clearly defined and decrease in the number of septa of connective tissue that crossed them was noted. The vessels in the inferior part of the articular disc did not reach the middle area of the disc (Figure 1 E,F).

Some macrophage-like cells that expressed CD 68 and fibroblast-like type B cells that express Hsp27 (Figure 2 A,C,E) appeared bottoms of the inferior articular cavity.

\section{Week 13}

All specimens studied during the thirteenth week showed the vessels located bottoms of the inferior articular cavity. Some vessels surrounded by fusiform cells protruded from the inferior sac bottoms, which corresponds to the primordium of the synovial villi (Figure 1G).

Panels B and D of Figure 2 show the positive control of the antibodies CD68 and Hsp27 in palatine tonsil and breast adenocarcinoma samples, respectively.

\section{Discussion}

According to Mérida-Velasco et al.,, ${ }^{1,2}$ the TMJ joint cavities are not formed synchronously. First, the inferior joint cavity begins to develop in the ninth week as small spaces or fissures appear between the articular disc and the mandibular condyle. Subsequently, the superior joint cavity begins to form approximately in the eleventh week of gestation, between the articular disc and the squamous part of the temporal bone.

The findings by Mérida-Velasco et al. ${ }^{1}$ contrast with those of Van der Linden et al., ${ }^{36}$ Sperber, ${ }^{37}$ Burdi,${ }^{38}$ and Ögutcen-Toller ${ }^{39}$ who reported that the inferior joint cavity begins to form during the tenth week of gestation, while the superior joint cavity begins to form from the eleventh week of gestation. According to Ohnuki, ${ }^{37}$ the inferior joint cavity above the mandibular condyle is still being formed during the twelfth week of development, while the superior joint cavity is only visible in the posterior region of the joint.

In humans, buccal movements begin during weeks 7 and 8 of development ${ }^{41}$ at the level of the incudomalleolar joint. ${ }^{42}$ TMJ movements help to form the joint cavity and their absence could results in congenital craniofacial anomalies. ${ }^{31}$ The presence of blood vessels in the articular disc of the TMJ of human fetuses has been described by many authors. Van der Linden et al..$^{36}$ noted that capillaries were distributed in the periphery of the anterior and posterior portions of the articular disc in human fetuses. However, they did not report any vessels in the central region of the articular disc. Wong et al. ${ }^{43}$ observed that in fetuses, 13 to 17.5 weeks of development vessels are

mainly located anteriorly and posteriorly, but no evidence of vascularization was found at the center of articular disc. Thilander et al. ${ }^{44}$ studied 61 specimens of articular disc aged 2 days to 26 years and concluded that vascularization only exists in the first year of life, after which it disappears.Interestingly, Sabú et al. ${ }^{45}$ observed vessels containing red blood cell in the central portion of the TMJ articular disc of human fetuses.

According to our findings, from the ninth week of development the number of vessels increases around the temporomandibular joint region, sending some vascular branches to the
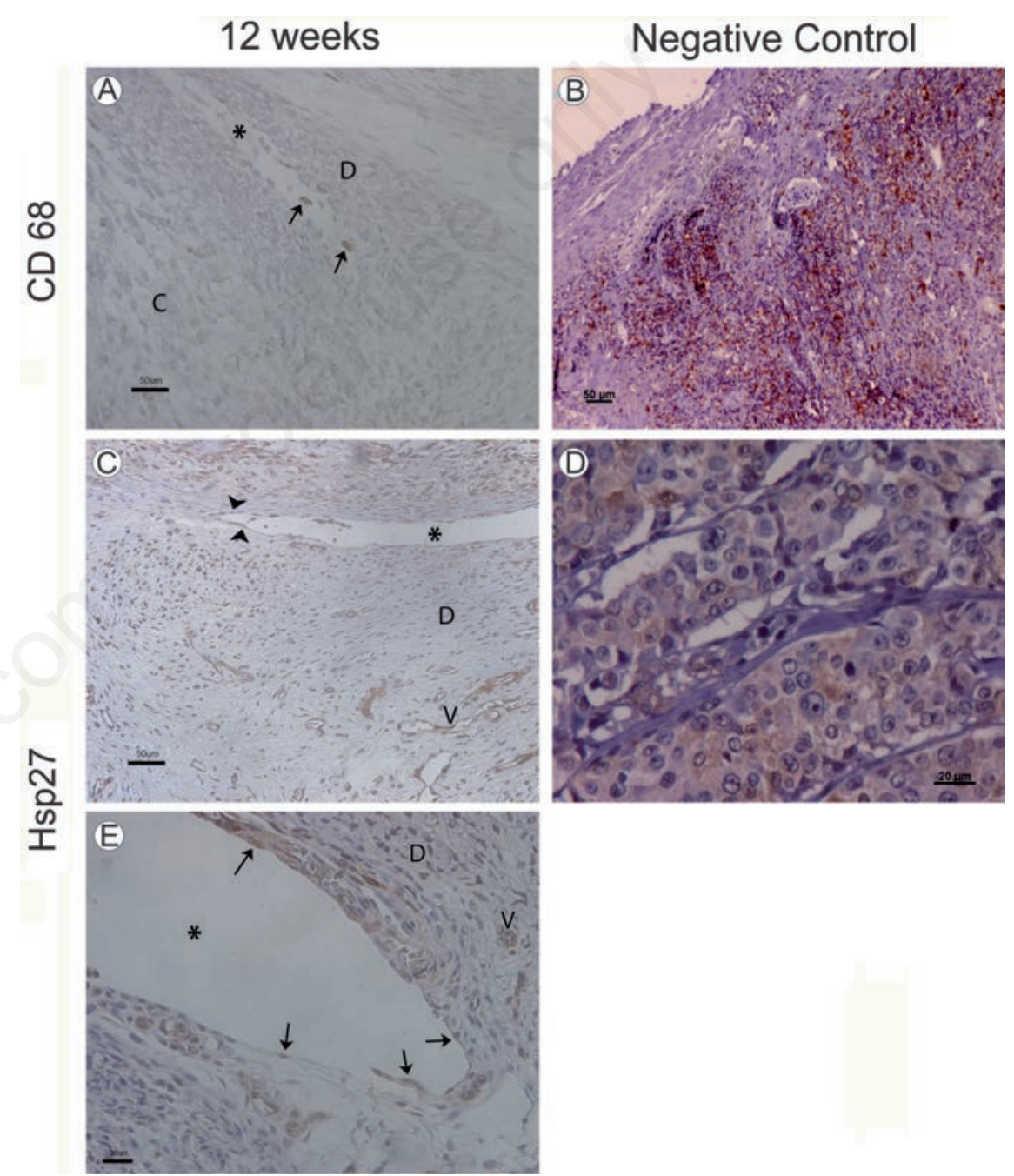

Figure 2. A) Human fetus ( $75 \mathrm{~mm} \mathrm{GL}$; week 12 of development); macrophage-like type A cells marked by CD68 antiboides; C, mandibular condyle; D, articular disc; asterisk, inferior joint cavity. B) Positive control; palatine tonsil; CD68 antibody. C) Human fetus (82 mm GL; week 12 of development); marked fibroblast-like type B cells by Hsp27 antibodies (arrowheads) in the synovial membrane and vessels (V); asterisk, superior joint cavity. D) Positive control; breast adenocarcinoma; HS27 antibody. E) Human fetus (82 mm GL; week 12 of development); marked fibroblast-like type B cells by Hsp27 antibodies (arrowheads) in the inferior articular cavity (asterisk). The walls of the vessels (V) are marked with Hsp27 antibodies; D, articular disc. 
periphery of the articular disc primordium. In specimens at eleven weeks of development, the vessels reach the central portion of the articular disc and fusiform-like cells separate the disc from the inferior articular cavity. During the twelfth week of development, the articular cavities are well defined and the vessels do not reach the central region of the articular disc. These findings can suggest that the vessels are necessary for the vascularization of the articular disc until the synovial membrane is well developed.

The synovial membrane of the TMJ is areolar and only this type of synovial membrane is characterized by the presence of two cell types in its intima layer: macrophage-like type A cells and fibroblast-like type $B$ cells. ${ }^{10-17}$ Macrophage-like types A cells contain numerous vesicles, vacuoles, and lysosomes. Their basic function is to engulf, by phagocytosis, the proteins and carbohydrates present in the synovial..$^{14,46,47}$ Fibroblast-like type B cells are ultrastructurally characterized by the presence of a well-developed rough endoplasmic reticulum with numerous secretory granules. . $^{12,13,16-19}$ Macrophage-like type A and fibroblast-like type $B$ cells in the synovial membrane can be identified by immunohistochemistry and transmission electron microscopy in fetuses, adults, and animals before and after birth..$^{10-17,30}$ Ikeda et $a l .{ }^{46}$ reported that macrophage-like type A cells in the synovial membrane of the TMJ of rats were only visible after birth. However, Sabú et al. ${ }^{48}$ found macrophage-like type A and fibroblast-like type B cells only during the gestational period.

Our findings confirm those of other authors, including ${ }^{10-14,16,17,19}$ who found both macrophage-like type A and fibroblast-like type $B$ cells in the synovial membrane before birth. During the $12^{\text {th }}$ week of development of the peripheral parts of the inferior articular cavity, macrophage-like type A and fibroblast-like type $B$ cells were marked by immunohistochemical reaction with the antibodies CD68 and Hsp27, respectively. Fibroblast-like type $\mathrm{B}$ cells were also marked in the peripheral portions of the superior articular cavity. These findings could suggest that from the twelfth week of development, with the articular cavities well formed, the synovial membrane is functional and the vessels are only seen in the peripheral areas of the articular disc. The synovial villi form from the thirteenth week of development. There is also a third type of cell not yet fully studied called an intermediate lining cell. ${ }^{48-51}$ More studies are necessary to determine the morphology and ultrastructure of these cells.

This study demonstrates that development of the synovial membrane depends on the fibroblast-like type B cells located on the surface of the synovial membrane and macrophage-like type A cells that supply the vessels. Our results also suggest that in human specimens at twelve weeks of development, the articular cavities are well formed and the synovial membrane begins to be functional.

\section{References}

1. Mérida-Velasco Jr, Rodríguez-Vázquez JF, Mérida-Velasco JA, Sánches-Montesinos I, Espín-Ferra J, et al. Development of the human temporomandibular joint. Anat Rec 1999;255:20-33.

2. Mérida-Velasco JR, Rodríguez-Vázquez JF, De la Cuadra Blanco C, Campos López R, Sánchez M, Mérida Velasco JA. Development of the mandibular condylar cartilage in human specimens of 10-15 weeks' gestation. J Anat 2009;214:56-64.

3 0'Rahilly R, Müller F. Human embryology \& teratology. 3rd ed. New York: Wiley-Liss; 2001.

4. Huang GTJ, Thesleff I. Stem cells in craniofacial development and regeneration. Hoboken: Wiley Blackwell; 2013.

5. Moraes LOC, Alvez CSR, Marques SR, Uzêda-Gonzales SQ, Vretos C, Smith RL, et al. Macroscopy and light microscopy of the discomallear passing through the petrotympanic fissure in human fetuses. Eur J Anat 2007;11:47-51.

6. Moraes LOC, Lodi FR, Gomes TS, Marques SR, Oshima CTF,Lancellotti CLP, et al. Immunohistochemical expression of types I and III collagen antibodies in the temporomandibular joint disc of human fetuses. Eur J Histochem. 2011;55:e24.

7. Kiga N. Histochemistry for studying structure and function of the articular disc of the human temporomandibular joint. Eur J Histochem 2012;56:e11.

8. Shibata S, Sakamoto Y, Baba 0, Qin C, Murakami G, Cho BH. An immunohistochemical study of matrix proteins in the craniofacial cartilage in midterm human fetuses. Eur J Histochem 2013;57:e39.

9. Fujikawa K, Yokohama-Tamaki T, Morita T, Baba 0, Qin C, Shibata S. An in situ hybridization study of perlecan, DMP1, and MEPE in developing condylar cartilage of the fetal mouse mandible and limb bud cartilage. Eur J Histochem 2015;59:2553.

10. Barland P, Novikoff AB, Harmerman D. Electron microscopy of the human synovial membrane. J Cell Biol1962;14:207-20.

11. Ghadially FN. Fine structure of synovial joints. London: Butterworths; 1983.

12. Dijkgraaf LC, De Bont LG, Boering G, Liem RS. Structure of the normal synovial membrane of the temporomandibular joint: a review of the literature. J Oral Maxillofac
Surg 1996;54:332-8.

13. Iwanaga T, Shikichi M, Kimatura $H$, Yanase H, Nozawa-Inoue K. Morphology and functional roles of synoviocytes in the joint. Arch Histol Cytol 2000;63:17-31.

14. Nozawa-Inoue K, Amizuka N, Ikeda N, Suzuki A, Kawano Y, Maeda T.Synovial membrane in the temporomandibular joint - its morphology, function and development. Arch Histol Cytol 2003;66:289-306.

15. Standring S. Gray's anatomy: the anatomical basis of clinical practice. 40th ed. Churchill Livingstone; 2008.

16. Murnane TW, Feagans WM. Fine structure of synovial lining cells in the squamosalmandibular joint of the rat. $J$ Dent Res 1970;49:1068-73.

17. Wysocki GP, Brinkhous KB, Hill C. Scanning electron microscopy of synovial membranes. Arch Path 1972;93:172-7.

18. Graabek PM. Ultrastructural evidence for two distinct types of synoviocytes in rat synovial membrane. J Ultra Res 1982;78: 321-39.

19. Shikichi M, Kitamura H, Yanase H, Konno A, Takahashi-Iwanaga $\mathrm{H}$, Iwanaga $\mathrm{T}$. Three-dimensional ultrastructure of synoviocytes in the horse joint as revealed by scanning electron microscope. Arch Histol Cytol 1999;62:219-29.

20. Grabowski PS, Wright PK, Van'T Hof RJ, Helfrich MH, Ohshima H, Ralston SH. Immunolocatization of inducible nitroc oxide synthase in synovium and cartilage in rheumatoid arthritis and osteoarthritis. Br J Rheumatol 1997;36:651-5.

21. Nozawa-Inoue K, Takagi R, Kobayashi Y, Ohashi Y, Maeda T. Immunocytochemical demonstration of the synovial membrane in experimentally induced arthritis of the rat temporomandibular joint. Arch Histol Cytol 1998;61:451-66.

22. Suzuki A, Nozawa-Inoue K, Ikeda N, Amizuka N, Ono K, Takagi R, et al. Development of the articular cavity in the rat temporomandibular joint with special reference to the behavior of endothelial cells and macrophages. Anat $\operatorname{Rec}[\mathrm{A}]$ Discov Mol Cell EvolBiol 2005;286:908-16.

23. Stevens CR, Mapp PI, Revell PA. A monoclonal antibody (Mab 67) marks type B synoviocytes. RheumatolInt 1990;10:103-6.

24. Wilkinson LS, Edwards JCW, Poston RN, Haskard DO. Expression of vascular cell adhesion molecule-1 in normal and inflamed synovium. Lab Invest 1993;68:82-8.

25. Edwards JCW. The nature and origins of synovium: experimental approaches to the study of synoviocyte differentiation. J Anat 1994;184:493-501.

26. Athanasou NA. Synovialmacrophages. Ann RheumDis1995;54:392-4.

27. Nozawa-Inoue K, Ajima H, Takagi R, 
Maeda T. Immunocytochemical demonstration in the synovial lining layer of the rat temporomandibular joint. Arch Oral Biol 1999a;44:531-4.

28. Andoh E, Kawano Y, Ajima H, NozawaInoue K, Kohno S, Takeyasu M. Expression of $25 \mathrm{kDa}$ heat shock protein by synovial type $\mathrm{B}$ cells of the mouse temporomandibular joint. Arch Oral Biol 2001;46: 947-54.

29. Nozawa-Inoue K, Amizuka N, Suzuki A, Maeda T. Immunocytolchemical localization of MAPKAPK-2 and Hsp25 in the rat temporomandibular joint. Anat Rec 2005; 284A:522-8.

30. Okamoto K, Kiga N, Shinohara Y, Tojyo I, Fujita S. Effect of interleukin-1beta and ehydroepiandrosterone on the expression of lumican and fibromodulin in fibroblastlike synovial cells of the human temporomandibular joint, Eur J Histochem 2015; 59:2440.

31. Holmes LB. Common malformations. New York: Oxford University Press; 2012.

32. 0'Rahilly R, Müller F. Developmental stages in human embryos: revised and new measurements. Cell Tissue Organs 2010;192:73-84.

33. McManus J, Mowry R. Técnica histológica. Madrid: Atika S/A; 1968.

34. Takagi K, Takada T, Amano H. A high peripheral microvessel density count correlates with a poor prognosis in pancreatic cancer. J Gastroenterol 2005;40:402-8.

35. Ramos-Vara JA. Technical aspects of immunohistochemistry. Vet Pathol 2005;
42:405-26.

36. Van der Linden EJ, Burdi AR, Jongh HJ. Critical periods in the prenatal morphogenesis of the human lateral pterygoid muscle, the mandibular condyle, the articular disc and medial articular capsule. Am J Orthod Dentofac Orthop 1987;91:22-8.

37. Sperber GH. Craniofacial embryology. 4th ed. Cambridge: Wright; 1989.

38. Burdi AR. The temporomandibular joint: a biological basis for clinical practice. 4th ed. Philadelphia: WB Saunders; 1991.

39. Ögutcen-Toller M. The morphogenesis of the human discomalleolar and sphenomandibular ligaments. J Craniofac Surg 1995;23:42-6.

40. Ohnuki H. On the formation of the temporomandibular joint cavity in the human fetus. Kaibogaku Zaisshi 2000;75:325-36.

41. Humphrey T. The development of mouth opening and related reflexes involving the oral area of human fetuses. Ala J Med Sci 1968;5:389-95.

42. Mérida-Velasco Jr, Rodríguez Vázquez JF, Jiménez Collado J. Meckelian articular complex. Eur Arch Biol 1990;101:447-53.

43. Wong GB, Weinberg S, Symington JM. Morphology of the developing articular disc of human temporomandibular joint. $\mathbf{J}$ Oral Maxillofac Surg 1985;43:565-9.

44. Thilander B, Carlsson GE, Ingervall B. Postnatal development of the human TMJ joint. Acta Odont Scand 1976; 34:117-26.

45. Sabú CRA, Moraes LOC, Uzêda-Gonzalez SQ, Marques SR, Vretos C, Aguillera AH, Scarpati GRSS, Harb LJC, Junior JAF,
Oshima C, Smith RL, Alonso LG. Ultra structural evidence of vascularization of the central zone of TMJ disc in human fetus. Eur J Anat. 2006;10:45-8.

46. Ikeda N, Nazawa-Inoue K, Takagi R, Maeda T. Development of the synovial membrane in the rat temporomandibular joint as demonstrated by immunocytochemistry for heat shock protein 25 . Anat Rec Discov Mol Evol Biol 2004;279:623-35.

47. Niwano M, Nozawa-Inoue K, Suzuki A, Ikeda N, Takagi R, Maeda T. Immunocytochemical localization of caveolin-3 in the synoviocytes of the rat temporomandibular joint during development. Anat Rec 2008;291:233-41.

48. Sabú CRA, Moraes LOC, Uzêda-Gonzalez SQ, Marques SR, Vretos C, Aguillera AH, et al. Morphology and ultrastructure of the TMJ disc in human fetuses 21 to 28 weeks old. Braz J Morphol Sci 2005;22:233-8.

49. Fell HB, Glauert AM, Barratt MEJ, Green R. The pig synovium I: the intact synovium in vivo and organ culture. J Anat 1976; 122: $663-80$.

50. Horký D. The ultrastructure of synovial membrane in the prenatal pig. Acta Vet Brno 1990;59:13-21.

51. Nagai H, Miyamoto Y, Nakata A, Hatakeyama S, Iwanami Y, Fukuda M. Isolation and characterization of synovial cells from the human temporomandibular joint. J Oral Pathol Med 2006;35:104-10. 